\title{
Conventional aortic valve replacement versus transcatheter aortic valve implantation: professional requirements for nurses
}

\author{
Tao Jiang ${ }^{1}$, Shaolian Hu ${ }^{1}$, Yang Wang ${ }^{1}$, Tan Yang ${ }^{2}$, Lihong Chen ${ }^{1}$, Daiying Zhang ${ }^{1}$, Yuhui Ding \\ ${ }^{1}$ The Operating Room, the Affiliated Hospital of the Southwest Medical University, Luzhou, China; ${ }^{2}$ Cardiovascular Department, the Affiliated \\ Hospital of the Southwest Medical University, Luzhou, China \\ Contributions: (I) Conception and design: T Jiang; (II) Administrative support: D Zhang, Y Ding; (III) Provision of study patients: S Hu; (IV) \\ Collection and assembly of data: Y Wang, L Chen; (V) Data analysis and interpretation: T Yang; (VI) Manuscript writing: All authors; (VII) Final \\ approval of manuscript: All authors. \\ Correspondence to: Tao Jiang. The Operating Room, the Affiliated Hospital of the Southwest Medical University, Luzhou, China. Email: 9318903@qq.com.
}

\begin{abstract}
Background At present, the recommendation grade of transcatheter aortic valve implantation (TAVI) for aortic valve stenosis (AVS) has increased in many guidelines. Establishing an optimized TAVI nurse team is essential for improving surgical quality and outcomes. We compared the professional requirements for nurses in two surgical approaches for aortic stenosis and the different roles of nurses in the surgical teams, with an attempt to further improve the training programs for specialized nurses.

Methods: The required professional knowledge and the role of nursing staff during TAVI or AVR (Conventional aortic valve replacement) were analyzed. These included knowledge on the pathophysiology of aortic stenosis, advantages and disadvantages of different heart valves, extracorporeal circulation, nursing cooperation during valve replacement, conventional surgical instruments and interventional consumables, surgical complications, radiation protection, operation of pacemakers, theory and operation of electric defibrillation. And the surgical team members and their roles, and doctor-patient satisfaction were also compared.
\end{abstract}

Results: TAVI had higher requirements for the basic knowledge of the pathophysiology of aortic stenosis, advantages and disadvantages of different heart valves, extracorporeal circulation and theory and operation of electric defibrillation. And the clinical professional knowledge of conventional surgical instruments and interventional consumables, surgical complications, radiation protection, nursing cooperation, operation of pacemakers were also higher required in TAVI. Doctor-patient overall satisfaction were higher in TAVI than AVR (95.8\% vs. $84.4 \%, 97.5 \%$ vs. $92.7 \%)$.

Conclusions: The professional requirements for nurses differs between TAVI and AVR. Comprehensive programs should be designed to develop the basic knowledge and professional training for future cardiac operation.

Keywords: Transcatheter aortic valve implantation (TAVI); surgery; nursing; training

Submitted Dec 30, 2020. Accepted for publication Apr 04, 2021.

doi: 10.21037/apm-21-290

View this article at: http://dx.doi.org/10.21037/apm-21-290

\section{Introduction}

Aortic valve stenosis (AVS) is the functional narrowing of the orifice of the aortic valve that impedes delivery of blood from the left ventricle (LV) to the systemic circulation. As the most common valvular lesion, AVS has a prevalence of $4 \%$ in adults above 65 years (1). AVS has an insidious onset in elderly patients. Once it becomes symptomatic, the prognosis is extremely poor without any intervention: the 2-year survival rate is $50 \%$, and the 5 -year survival rate drops to $20 \%(2)$.

Transcatheter aortic valve implantation (TAVI) is an 
emerging technology that allows for the implantation of a prosthetic heart valve without the need for open heart surgery or cardiopulmonary bypass. During this procedure, a manufactured prosthetic valve mounted on a stent is manipulated into the position of the diseased aortic valve through one of the blood vessels. TAVI has emerged as an excellent alternative for patients who are inoperable or at high surgical risk (3). It was officially listed as a treatment for AVS in Western guidelines in 2012, and its recommendation grade has gradually increased. In China, TAVI was first performed in 2010; since the interventional valve began to be marketed with independent intellectual property rights in 2017, TAVI has developed rapidly.

With the innovation of new technologies, the nursing staff levels and the quality of care must be kept up to date with the emerging TAVI, and comprehensive care for TAVI patients is essential for providing optimal care strategies and improving patient prognosis (4). Due to the complexity of TAVI in case selection, management, and other aspects of nursing care, the competencies and expertise of nurses need to be further strengthened and integrated. Nurses may even play a leadership role in a TAVI team to facilitate an efficient, effective, and sustainable TAVI program.

Just because we are conventional cardiac surgery team that performed TAVI work, we have deep impression of the difference of the two methods for aortic stenosis disease, so in our paper, we want to give some advice for future professional training. Here we compared the different nursing requirements for conventional aortic valve replacement (AVR) and TAVI in terms of theoretical knowledge, team role, prognosis, and satisfaction, with an attempt to further optimize the training programs for specialized nurses. We present the following article in accordance with the MDAR checklist (available at http:// dx.doi.org/10.21037/apm-21-290).

\section{Methods}

From 2020.7 to $2020.11,5$ TAVI operation and 5 conventional AVR operation were selected. The indication for TAVI has based on the "2017 ESC/EACTs and AHA/ ACC guideline for the management of valvular heart disease". The following indicators were collected: members of two different surgical teams; the basic and clinical professional knowledge requirement, doctor-patient satisfaction.

The study was conducted in accordance with the Declaration of Helsinki (as revised in 2013). The study was approved by Ethics Committee of Affiliated Hospital of Southwest Medical University (No. L2019003) and informed consent was taken from all individual participants.

\section{Members of two different surgical teams}

\section{AVR team}

In an AVR team, leadership largely lies with the cardiac surgeon, and all other team members must follow the surgeon's instructions, including those involving surgical instruments, consumables, and even surgical habits.

The members of an AVR team include the following: (I) the cardiac surgeon, whose responsibilities include preoperative patient screening and evaluation, determination of surgical indications, communication with the patient and family, performing valve implantation, postoperative monitoring, and follow-up; (II) the anesthesiologist, whose responsibilities include preoperative evaluation, maintenance of anesthesia during surgery, and postoperative monitoring and management; and (III) the ultrasonographer, whose responsibilities include preoperative evaluation and intraoperative transesophageal echocardiographic measurements of the sizes of valve annulus and aortic root, evaluation of left ventricular function, detection of the position and function (e.g., regurgitation and pressure gradient) of the implanted valve, and detection of perivalvular leak (if any).

\section{TAVI team}

The leader of a TAVI team can be either a cardiologist or a cardiac surgeon. Different leaders have slightly different requirements on team members. The members of a TAVI team include the following: (I) the interventional cardiologist, whose responsibilities include patient referral and selection, coronary and peripheral angiography, consultations with surgeons, case presentation to the TAVI team, communication with patient and family, coronary stent placement, temporary balloon valvuloplasty, primary/ secondary operator for implantation, and follow-up; (II) the cardiac surgeon, whose responsibilities include patient referral and screening, risk assessment for TAVI, consultations with cardiology interventionalists, patient presentation to the TAVI team, communication with the patient and family, primary/secondary operator for high-risk AVR, vascular access, extracorporeal membrane oxygenation and surgical preparation (when necessary), and follow-up; (III) the cardiac radiologist, whose responsibilities include preoperative assessment, involving measurement of aortic annulus size, distance to the orifice of coronary artery, degrees of vascular calcification and stenosis, vascular 
accesses (femoral artery, iliac artery, and left axillary artery), and procedure optimization, involving predetermination of fluoroscopic angles; (IV) the anesthesiologist, whose responsibilities include preoperative evaluation, maintenance of anesthesia during surgery, and postoperative monitoring and management; and $(\mathrm{V})$ the ultrasonographer, whose responsibilities include preoperative evaluation and intraoperative transesophageal echocardiographic measurements of the sizes of valve annulus and aortic root, evaluation of left ventricular function, detection of mitral regurgitation, assessment of the pericardial condition, and assessment of the position and function (e.g., regurgitation and pressure gradient) of the implanted valve.

\section{Knowledge requirement analysis}

The required professional knowledge and the role of nursing staff during TAVI or AVR were analyzed. The knowledge included pathophysiology of aortic stenosis, advantages and disadvantages of different heart valves, knowledge of extracorporeal circulation, nursing cooperation during valve replacement, familiarity with conventional surgical instruments and interventional consumables, surgical complications, radiation protection, knowledge and operation of pacemakers, theory and operation of electric defibrillation, surgical team members and their roles.

\section{Doctor-patient satisfaction.}

In order to assess the doctor satisfaction with the nursing care offered by nurses with different training backgrounds in the TAVI team, three nursing supervisors who were familiar with the theoretical knowledge of conventional AVR but had never received TAVI-related training, and three nursing supervisors who had received systematic training on TAVI, were separately arranged as the main nursing leaders of the surgical teams. Five TAVI operators were randomly surveyed using a self-designed questionnaire form in terms of overall satisfaction with surgical cooperation, satisfaction with compliance, satisfaction with communication, satisfaction with professional theoretical knowledge, and whether they would like to cooperate again.

In order to assess patients' satisfaction with nurses with or without the theoretical basis of TAVI, three nursing supervisors with knowledge of conventional AVR but who had not received training on TAVI, and three nursing supervisors who had received systematic training on TAVI, were separately arranged as the nursing leaders during the surgeries for five patients (including admissions, perioperative care, and postoperative follow-up). Questionnaire-based survey was randomly carried out in terms of satisfaction with admission education, preoperative psychological care, patients' awareness of their own surgery, intraoperative comfort, and overall satisfaction.

\section{Statistical analysis}

The satisfaction was compared with chi square test, and the difference was statistically significant with $\mathrm{p}$ less than 0.05 .

\section{Results}

\section{Duties and requirements of nurses}

\section{Nurses in an AVR team}

The duties of nurses in an AVR team included perioperative nursing (including preoperative and intraoperative psychological care) and assessment, preparation of the environment in the operating room, preparation of intraoperative consumables and instruments, cooperation with surgeons to complete surgical operations, cooperation with surgeons to complete emergency management, body temperature management and pressure sore prevention, and management of various pipelines.

\section{Nurses in a TAVI team}

The duties of nurses in a TAVI team included discussion with the surgeons to optimize the management of the surgical procedure; preoperative psychological care and assessment, assessment and preparation of the environment in the operating room, preparation of special consumables and instruments during the operation, radiation protection; coordination with the anesthesiologist for pacing and defibrillation, cooperation with the interventional cardiologist/surgeon to complete the operation, cooperation with the team in the management of emergencies (e.g., serious complications), cooperation with the valve engineer to complete valve assembly, and postoperative care and follow-up.

Therefore, TAVI has special requirements for nurses including basic theoretical knowledge, radiation protection, pathophysiology of the disease, management of complications, use of electrophysiological equipment, and preparation of routine and special consumables for the intervention.

From Table 1 and Table 2, we can find that the TAVI 
Table 1 Requirements on theoretical knowledge for nurses in different surgical teams

\begin{tabular}{|c|c|c|c|c|c|c|c|}
\hline & $\begin{array}{l}\text { Basic theory of nursing care } \\
\text { during cardiac surgeries }\end{array}$ & $\begin{array}{l}\text { Theory of } \\
\text { radiation }\end{array}$ & $\begin{array}{c}\text { Cardiac } \\
\text { electrophysiology }\end{array}$ & Surgical steps & $\begin{array}{l}\text { Extracorporeal } \\
\text { circulation }\end{array}$ & Pathophysiology & Complications \\
\hline $\begin{array}{l}\text { AVR } \\
\text { team }\end{array}$ & Required $(+++)$ & Required (+) & Required (+) & Be familiar with & Be proficient in & Be familiar with & Understand \\
\hline $\begin{array}{l}\text { TAVI } \\
\text { team }\end{array}$ & Required $(+++)$ & Required (+++) & Required $(+++)$ & Be proficient in & Be proficient in & Be proficient in & Be proficient in \\
\hline
\end{tabular}

Table 2 Requirements on knowledge of instruments, consumables, and monitoring for nurses in different surgical teams

\begin{tabular}{|c|c|c|c|c|c|c|c|}
\hline & $\begin{array}{l}\text { Routine surgical } \\
\text { instruments }\end{array}$ & Defibrillators & $\begin{array}{l}\text { Interventional } \\
\text { consumables }\end{array}$ & Pacemakers & $\begin{array}{l}\text { Classification of } \\
\text { prosthetic valves }\end{array}$ & $\begin{array}{c}\text { Participation in } \\
\text { intraoperative } \\
\text { monitoring }\end{array}$ & $\begin{array}{l}\text { Special consumables } \\
\text { (balloons, graspers, etc.) }\end{array}$ \\
\hline $\begin{array}{l}\text { TAVI } \\
\text { team }\end{array}$ & Be proficient in & Be proficient in & Be proficient in & Be proficient in & Be proficient in & Control & Be proficient in \\
\hline
\end{tabular}

AVR, aortic valve replacement; TAVI, transcatheter aortic valve implantation.

Table 3 Transcatheter aortic valve implantation (TAVI) operators' evaluation of nurses with or without training on TAVI

\begin{tabular}{|c|c|c|c|c|c|c|c|}
\hline $\begin{array}{l}\text { Training } \\
\text { background of } \\
\text { TAVI }\end{array}$ & $\begin{array}{l}\text { Satisfaction with } \\
\text { professional } \\
\text { and theoretical } \\
\text { knowledge (\%) }\end{array}$ & $\begin{array}{c}\text { Satisfaction with } \\
\text { communication } \\
(\%)\end{array}$ & $\begin{array}{l}\text { Satisfaction } \\
\text { with } \\
\text { compliance } \\
(\%)\end{array}$ & $\begin{array}{c}\text { Satisfaction with } \\
\text { cooperation in } \\
\text { handling unexpected } \\
\text { events }(\%)\end{array}$ & $\begin{array}{l}\text { Satisfaction with } \\
\text { familiarity of } \\
\text { consumables (\%) }\end{array}$ & $\begin{array}{l}\text { Satisfaction of } \\
\text { cooperation } \\
\text { with surgical } \\
\text { procedures (\%) }\end{array}$ & $\begin{array}{c}\text { Overall } \\
\text { satisfaction } \\
\text { (\%) }\end{array}$ \\
\hline $\begin{array}{l}\text { With training on } \\
\text { TAVI }\end{array}$ & $95.1 \pm 33.4$ & $93.7 \pm 22.6$ & $98.2 \pm 32.7$ & $94.7 \pm 30.4$ & $97.0 \pm 21.6$ & $97.1 \pm 36.3$ & $95.8 \pm 31.4$ \\
\hline $\mathrm{t}$ & 3.58 & 2.63 & 1.95 & 2.75 & 5.69 & 2.71 & 5.15 \\
\hline$P$ & 0.02 & 0.03 & 0.04 & 0.03 & 0.00 & 0.03 & 0.01 \\
\hline
\end{tabular}

team had higher and more comprehensive requirements for nurses in terms of the theoretical knowledge about radiation, cardiac electrophysiology, pathophysiology of the disease, the knowledge about complications and surgical procedures, the use of interventional instruments/ consumables and pacemaker, and the participation in intraoperative monitoring.

\section{Doctor and patient satisfaction with nursing care offered by nurses with different training backgrounds in the TAVI team}

Overall, nurses with TAVI knowledge background were more likely to communicate with doctors and patients, and their satisfaction was higher.

\section{Operators' evaluation of nurses with different training background}

From Table 3, we find that the operators were more satisfied with nurses with a training background of TAVI in terms of professional knowledge, effective communication, compliance, cooperation in handling unexpected events, familiarity with consumables, and surgical cooperation. 
Table 4 Patient satisfaction with the nursing care offered by nurses with or without training on transcatheter aortic valve implantation (TAVI)

\begin{tabular}{|c|c|c|c|c|c|c|c|}
\hline $\begin{array}{l}\text { Training } \\
\text { background of } \\
\text { TAVI }\end{array}$ & $\begin{array}{c}\text { Satisfaction } \\
\text { with admission } \\
\text { education (\%) }\end{array}$ & $\begin{array}{c}\text { Preoperative } \\
\text { psychological } \\
\text { care (\%) }\end{array}$ & $\begin{array}{c}\text { Patients' awareness } \\
\text { of their own surgery } \\
\text { (\%) }\end{array}$ & $\begin{array}{l}\text { Intraoperative } \\
\text { comfort (\%) }\end{array}$ & $\begin{array}{c}\text { Satisfaction with } \\
\text { postoperative } \\
\text { recovery }(\%)\end{array}$ & $\begin{array}{l}\text { Satisfaction with } \\
\text { communication at } \\
\text { discharge }(\%)\end{array}$ & $\begin{array}{c}\text { Overall } \\
\text { satisfaction } \\
(\%)\end{array}$ \\
\hline $\begin{array}{l}\text { Without training } \\
\text { on TAVI }\end{array}$ & $95.7 \pm 30.7$ & $92.8 \pm 25.8$ & $85.2 \pm 29.0$ & $90.3 \pm 28.3$ & $94.7 \pm 32.6$ & $93.2 \pm 30.5$ & $92.7 \pm 28.8$ \\
\hline$P$ & 0.08 & 0.04 & 0.03 & 0.04 & 0.06 & 0.04 & 0.05 \\
\hline
\end{tabular}

\section{Patients' evaluation of nurses with different training background}

From Table 4, we find that although there was no significant difference in the satisfaction with admission education and the satisfaction with postoperative recovery, patients were significantly more satisfied with nurses with a training background of TAVI in terms of preoperative psychological care, patients' awareness of their own surgery, intraoperative comfort, and satisfaction with communication at discharge.

\section{Discussion}

As interventional techniques continue to improve and the quality of interventional valves are rapidly rising, the recommendation grade of TAVI for AS has increased annually in many guidelines. More hospitals in China are performing TAVI for more patients. Whereas establishing an optimized TAVI team is important for improving surgical quality and outcomes, nurses are playing increasingly critical roles in the TAVI team. As shown in our current studies, both operators and patients were more satisfied with nurses who had been trained on TAVI. This has put forward higher requirements on the comprehensive quality of nursing staff, and it is urgent to train nurses with different knowledge and skill backgrounds to meet the necessities of current technologies and related teamwork protocols.

According to the Consensus Statement of Standards for Interventional Cardiovascular Nursing Practice published in 2018, interventional cardiovascular nursing is a critical care nursing specialty providing complex nursing interventions to patients prone to clinical deterioration; consequently, appropriate guidance needs to be provided to assist health care providers in developing their workforce development and educational policies to minimize the risk for adverse events (5). Despite the widespread acceptance of the consensus, no relevant consensus documents or guidelines have been developed in China.

Zheng et al. pointed out that nursing staff has an important role in the prevention, detection, and management of complications in TAVI (6). Estes et al. (4) noted that the time immediately after valve implantation is the period in which nurses may exert their greatest impact, in particular in predicting and monitoring vascular complications, stroke, acute kidney injury, and new-onset atrial fibrillation. Furthermore, patients and families may have many questions regarding home care and activity restrictions at discharge; the nurses should listen carefully to all questions and concerns and be well prepared to answer questions and provide written information to facilitate recovery. Patients and families should be instructed on the use of all medications, especially anticoagulants. Education of patients and their families is particularly important because life-threatening complications can occur after discharge. Therefore, nurses play crucial roles before, during, and after surgery and therefore they must be highly knowledgeable and have good communication skills (7).

As the number of TAVI treatment centers and procedures increases, nurses must acquire more knowledge (including in myocardial electrophysiology, operation of radiology equipment, radiation protection, and image recognition) to be better integrated into a TAVI team, in which they can better understand the procedure and possible complications, offer more efficient care through rapid monitoring and intervention, and achieve better longterm patient outcomes. Accordingly, specialty nurse training programs should be tailored and redesigned to meet these challenging requirements in clinical settings, especially the nursing care during TAVI. 
So we suggest that, future training program for cardiac operation nurse team, the basic knowledge, such as theory of radiation, cardiac electrophysiology, extracorporeal circulation, pathophysiology of heart diseases, complications of cardiac operation should be listed, and the professional skills, such as pacemaker and defibrillator manipulating, special instruments (balloons, graspers, etc.) understanding, intraoperative monitoring also should be added.

\section{Acknowledgments}

Funding: Project of Sichuan Provincial Department of Science and Technolog (No. 2018JY0405 and No. 2018JY0080); Collaborative Innovation Center for Prevention and Treatment of Cardiovascular Disease of Sichuan Province (Xtcx2019-04 and Xtcx2016-20).

\section{Footnote}

Reporting Checklist: The authors have completed the MDAR checklist. Available at http://dx.doi.org/10.21037/apm-21-290

Data Sharing Statement: Available at http://dx.doi. org/10.21037/apm-21-290

Conflicts of Interest: All authors have completed the ICMJE uniform disclosure form (available at http://dx.doi. org/10.21037/apm-21-290). The authors have no conflicts of interest to declare.

Ethical Statement: The authors are accountable for all aspects of the work in ensuring that questions related to the accuracy or integrity of any part of the work are appropriately investigated and resolved. The study was conducted in accordance with the Declaration of Helsinki (as revised in 2013). The study was approved by Ethics
Committee of Affiliated Hospital of Southwest Medical University (No. L2019003) and informed consent was taken from all individual participants.

Open Access Statement: This is an Open Access article distributed in accordance with the Creative Commons Attribution-NonCommercial-NoDerivs 4.0 International License (CC BY-NC-ND 4.0), which permits the noncommercial replication and distribution of the article with the strict proviso that no changes or edits are made and the original work is properly cited (including links to both the formal publication through the relevant DOI and the license). See: https://creativecommons.org/licenses/by-nc-nd/4.0/.

\section{References}

1. Ozkan A, Kapadia S, Tuzcu M, et al. Assessment of left ventricular function in aortic stenosis. Nat Rev Cardiol 2011;8:494-501.

2. Horstkotte D, Loogen F. The natural history of aortic valve stenosis. Eur Heart J 1988;9 Suppl E:57-64.

3. Leon MB, Smith CR, Mack M, et al. Transcatheter aortic-valve implantation for aortic stenosis in patients who cannot undergo surgery. N Engl J Med 2010;363:1597-607.

4. Estes BA, Kalra A. Contemporary nursing care in transcatheter aortic valve replacement. J Vasc Nurs 2018;36:186-8.

5. White K, Macfarlane H, Hoffmann B, et al. Consensus Statement of Standards for Interventional Cardiovascular Nursing Practice. Heart Lung Circ 2018;27:535-51.

6. Zheng $\mathrm{M}$, Qin R, Zeng $\mathrm{Y}$, et al. Complications in Transcatheter Aortic Valve Implantation and Its Nursing: A 24-case Study. Journal of Nursing 2014,3:48-50.

7. Ruel M, Dickie S, Chow BJ, et al. Interventional valve surgery: building a team and working together. Semin Thorac Cardiovasc Surg 2010;22:145-9.
Cite this article as: Jiang T, Hu S, Wang Y, Yang T, Chen L, Zhang D, Ding Y. Conventional aortic valve replacement versus transcatheter aortic valve implantation: professional requirements for nurses. Ann Palliat Med 2021;10(4):4369-4374. doi: 10.21037/apm-21-290 